\title{
Differences in emotional personality traits and stress between sustained hypertension and normotension
}

\author{
William Gerin \\ Hypertension Research (2010) 33, 194; doi:10.1038/hr.2009.223; published online 8 January 2010
}

$\mathrm{P}$ erhaps the oldest problem in the field of psychosomatic medicine concerns the relationship between personality and blood pressure. Freud hypothesized, in the 1930s, that persons who tend to repress their anger-to hold it in-would have higher blood pressure than those who were able to express their anger, ${ }^{1}$ and, indeed, this question was the subject of what are considered the first papers published in this field. ${ }^{2,3}$ It is now some 80 years later, and still, we have only a rudimentary understanding of the role of personality in the development of hypertension.

One factor that is implicated in obscuring the relationships between personality traits and blood pressure is the quality of the blood pressure measurements on which the analyses are based. As with any measurement (including that of personality variables), measurements can be of poorer or better quality, defined in terms of their reliability and validity. When based on measurements with poor reliability and/or validity, relationships that might truly hold in the population will necessarily be obscured. Thus, it is vital to understand the role of the measurement biases if we are to better understand the role that personality traits may have in hypertension.

Professor García-Vera and her colleagues have, in the accompanying manuscript, studied differences in anxiety, depression and stress between persons diagnosed as normotensive and those diagnosed as hyper- tensive. ${ }^{4}$ This is a hugely important focus, as it has the potential to contribute, ultimately, to the development of non-pharmacological interventions to reduce blood pressure in hypertensive patients.

Typically, diagnosis of hypertension is based solely on blood pressure measurements obtained in the physician's office. However, as the authors point out, $20-30 \%$ of such diagnoses typically include persons who present with elevated office blood pressures only when in the physician's office, but, outside the office, are normotensive. This has been referred to as 'isolated office hypertension' or 'white coat hypertension', and much testing has shown that the prognosis for patients given this diagnosis is no worse than that for those diagnosed as normotensive. ${ }^{5}$ One result of this 'white coat' bias is that the determinants of 'true' hypertension (defined here as hypertensive-range blood pressure values assessed both inside and outside of the physician's office) will be diluted to the extent that the diagnosis includes 'not true' (that is, 'white coat') hypertensives. Thus, the inclusion of up to $30 \%$ white coat hypertensives in what is thought to be a 'true' hypertensive sample would add heterogeneity, and, therefore, will introduce error in the mean, thus making it difficult to observe systematic relationships with other outcomes. Based on this, the authors measured blood pressure both in the doctor's office, and had the participants measure their blood pressure at home and at work, using home blood pres- sure monitors. This allowed them to obtain a 'purer' sample of both 'true hypertensives', by excluding those with normal home pressures, and normotensives, by excluding those with elevated home blood pressures. In theory, this procedure should allow relationships between the blood pressure and other measures-depression, anxiety and stress, in this instance-to emerge.

In fact, in what is often a confusing literature that abounds with ambiguous results, García-Vera et al. ${ }^{4}$ have obtained clear, hypothesis-driven results that make an important contribution to this literature. The role of depression, especially, has been neglected in this area. Moreover, and of equal significance, the authors have laid out a foundation for how blood pressure measurements should be collected for purposes of diagnosis.

\footnotetext{
1 Gleiberman L. Repressive/defensive coping, blood pressure, and cardiovascular rehabilitation. Curr Hypertens Rep 1939; 9: 7-12.

2 Alexander FG. Emotional factors in essential hypertension: presentation of a tentative hypothesis. Psychosom Med 1939; 1: 175-179.

3 Dunbar E. Emotions and Bodily Changes: A Survey of Literature on Psychosomatic Interrelationships 1910 1945, 3rd edn. Columbia University Press: New York, 1947.

4 García-Vera MP, Sanz J, Espinosa R, Fortún M, Magán I. Differences in emotional personality traits and stress between sustained hypertension and normotension. Hypertens Res 2010; 33: 203-208.

5 Pickering TG. White coat hypertension: Should it be treated or not? Cleveland Clin J Med 2002; 8: 584-585.
} 